\title{
Effect of Meditation on Auditory Reaction Time in First Mbbs Students of D.Y. Patil Medical College, Kolhapur
}

\author{
Pandian $\mathbf{M}^{1}$, Dr. Padmaja $\mathrm{R}^{2^{*}}$, Dr. Amruta N. Kumbhar ${ }^{3}$ \\ ${ }^{1}$ Tutor, Department of Physiology, D.Y.Patil Medical College, Kolhapu,r Maharashtra, India \\ ${ }^{2}$ Desai, Professor \& HOD, Department of Physiology, D.Y.Patil Medical College, Kolhapur, India \\ ${ }^{3}$ Assistant Professor, Department of Physiology, D.Y.Patil Medical College, Kolhapur, India
}

DOI: $10.36348 / \mathrm{sb} .2019 . \mathrm{v} 05 \mathrm{i} 11.007$

| Received: 14.09.2019 | Accepted: 23.09.2019 | Published: 28.11 .2019

*Corresponding author: Dr. Padmaja R

Abstract

Background :In the recent years, yoga was found to causes a betterment and improvement in the health of human being without ailments. The meditation play a major role in society by improving the significant changes in bodily activities such as maintain the stress level, alertness, homeostasis, anxiety, vascular system, memory power etc .The improvement of meditation in the reaction time is important, especially in auditory reaction time )ART .(Therefore, a need techniques or courses can improve the reaction time .Hence, this study intended to show its utility as a short course for improving the auditory reaction time Aim \& Objectives :To find out effect of meditation on auditory reaction time in medical students by recording auditory reaction time before \& after meditation for six months .Methods :The study was conducted on total 100 first MBBS students) boys \& girls( of D.Y .Patil Medical College, Kolhapur .Students in the age group of 18-25 years were included by simple random sampling technique. The Auditory reaction time was assessed before and after the yoga sessions .Results :There was a reduction in the alert response of auditory reaction time for both the ears .The decrease was statistically significant )P $<0.0001$.(Conclusion $:$ It can be concluded that, a short course of meditation has a beneficial effect on the auditory reaction time . The regular practice of Meditation can be used as a tool to improve the health and well-being of an individual and enhances the reaction time .

Keywords :Auditory Reaction Time) ART(, Meditation, Medical student.

Copyright @ 2019: This is an open-access article distributed under the terms of the Creative Commons Attribution license which permits unrestricted use, distribution, and reproduction in any medium for non-commercial use (NonCommercial, or CC-BY-NC) provided the original author and source are credited.

\section{INTRODUCTION}

The yogic and meditation techniques have been convincing the scientific basis of physiological changes, which aim at physical and mental self-culture [1-3] .It has been reported that remarkable feats of endurance [4, 5] . They can control their autonomic functions [6, 7]. Previous research evidence proved that yoga practice improves cardiorespiratory efficiency, decrease the auditory reaction time significantly $[1,8$, 10] and Performance quotient [1] .In an earlier work from our laboratories, we have demonstrated that subjects trained in yoga can achieve a state of deep psychosomatic relaxation associated with a significant reduction in oxygen consumption [9] .These studies indicate that yoga has practical application for improving human performance.

\section{MATERIAL \& METHODS \\ Study population}

Present study was conducted in the Yoga lab of Department of Physiology, D.Y .Patil Medical College Kolhapur. The permission was obtained from Institutional Ethics Committee )IEC .(The study was conducted on total 100 first MBBS students) boys \& girls( of D.Y .Patil Medical College, Kolhapur . Students in the age group of 18-25 years were included by simple random sampling technique .

The participation in the study was purely voluntary by the students. The selected first year students were interviewed personally and their personal and family history were taken .Their personal history included their daily routine, dietary habit; exercise habit etc . 
The study subjects were selected according to following preset inclusion and exclusion criteria .All the participants were briefed in detail regarding the nature of study. Written informed consent was obtained from each of them .

\section{Inclusion criteria}

- Male and female students were included

- Healthy students without any Systemic complications were included

- Students regular in meditation practice were included.

\section{Exclusion criteria}

- Students with physical/psychological illness

- Individuals under any kind of medications

- Individuals with Previously diagnosed sleep disorders .

\section{METHODS}

First year medical students were counselled and motivated for taking part in study .In this, study a choice reaction time in the form of auditory signals )Tone \& Click sounds (were used .The examiner sits with master )primary (controls and subject sits on other side with )secondary( controls. The two were separated with the help of opaque partition so, that the subject does not see which switch the examiner presses .

Once the unit is switched on, the examiner presents Tone \& Click sounds of auditory signals to the subject .Now, the subject immediately responds by pressing the corresponding switch on his/her side .

The time duration between the application of stimulus by examiner and the response from the subject is the auditory reaction time, which is recorded on reaction time apparatus in 0.5 milliseconds .Four such test recordings were done after two to three practice sessions .The average of these recordings was taken as final record for each subject .

One set of recordings was taken before meditation practice and the second set of recordings was taken after 5 months of meditation practice respectively. Statistical analysis was done with the help of wilcoxon rank sum test.

\section{Study procedure}

Written informed consent of all the participants was taken before the study. History taking, general examination and systemic clinical examination will be done before the procedure. It was followed by 30 mins of meditation training by Yoga trainer, preferably on empty stomach.

\section{Yoga training program}

- Warmup / Exercise First, we requested students to jump slowly followed by increase in the speed with hand movements.

- Small prayer (Gayatri mantra)

- Nadishodhan Pranayama with Chinmudra

Students have to use their fingers as per the instructions given by the yoga trainer .Thumb was kept on right nostril for opening and closing of the nostril, index and middle finger were used for Agnya Chakra )between two eyebrows(, ring and little finger were kept on left nostril for opening and closing of the nostril .It involves slow and deep breathing within the comfort zone .The left hand was kept on the lap with chinmudra.

\section{Omkar Chanting}

Students were requested to keep their eyes closed, interlock their right and left fingers, and keep them near abdomen. They performed 14 cycles, in that first two cycles were done by open mouth chanting . Remaining 12 cycles were Bhramari Pranayam.

Students were requested to keep their eyes close and focus on their breathing slowly inhaling as well as exhaling for next 3 minutes with chinmudra.

- Students were requested to rub their palms and apply on their face and body whatever energies were gained in this session.

- After this, there is a prayer (Om shanti shanti) and the session was ended.

- Next was deep relaxation technique, It allows the body to absorb all the benefits of meditation and breathing exercises. Legs were spread and this encourages the release of physical tension and mental stress.

\section{RESULTS}

\begin{tabular}{|l|l|l|l|l|}
\hline \multicolumn{2}{|l|}{$\begin{array}{l}\text { Reaction Time } \\
\text { )0.5 milliseconds }(\end{array}$} & $\begin{array}{l}\text { Before yoga } \\
\text { MEAN } \pm \text { SD }\end{array}$ & $\begin{array}{l}\text { After yoga } \\
\text { MEAN } \pm \text { SD }\end{array}$ & $\begin{array}{l}\text { p-value } \\
\text { WILCOXON RANK SUM TEST }\end{array}$ \\
\hline $\begin{array}{l}\text { Auditory } \\
\text { )CLICK( }(\end{array}$ & Right E & $0.219 \pm 0.115$ & $0.184 \pm 0.101$ & $\mathrm{P}=0.0078^{* *}$ \\
\cline { 2 - 5 } & Left E & $0.17 \pm 0.1$ & $0.16 \pm 0.099$ & $\mathrm{P}<0.0001^{* *}$ \\
\hline \multirow{2}{*}{$\begin{array}{l}\text { Auditory } \\
\text { )Tone( }\end{array}$} & Right E & $0.233 \pm 0.086$ & $0.226 \pm 0.079$ & $\mathrm{P}<0.0001^{* *}$ \\
\cline { 2 - 5 } & Left E & $0.18 \pm 0.094$ & $0.199 \pm 0.064$ & $\mathrm{P}<0.0001^{* *}$ \\
\hline
\end{tabular}

In present study there was no significant ) $\mathrm{P}=0.0078\left({ }^{* *}\right.$ decrease in auditory reaction time in right ear for click sound )from $0.219 \pm 0.115$ to $0.184 \pm$ 0.101 millisecond (after meditation. There was 
Pandian M et al., Sch Bull, Nov 2019; 5(11): 644-647

significant $) \mathrm{P}<0.001(* *$ decrease in auditory reaction time in left ear for click sound )from0.17 \pm 0.1 to $0.16 \pm$ 0.099 millisecond (after meditation.

There was no significant $) \mathrm{P}<0.001(* *$ decrease in auditory reaction time in right ear for tone sound )from $0.233 \pm 0.086$ to $0.226 \pm 0.079$ millisecond (after meditation.

There was significant $) \mathrm{P}<0.001(* *$ decrease in auditory reaction time in left ear for tone sound )from $0.18 \pm 0.094$ to $0.199 \pm 0.064$ millisecond (after meditation.

\section{DISCUSSION}

The Reaction time is used to measure the performance of an individual and to measure function of sensory motor association .It is a non-invasive and a simple test for peripheral as well as central neural structures .In this study, it has been demonstrated that practicing short-term meditation produces a significant shortening in ART in first year medical students. Shortening of ART can be explained by increase in sensory motor conduction velocity and/or faster information processing in the central nervous system.

The mind and body is interlinked and that has been scientifically proved.The homeostatic condition of the body is regulated by the limbic system of the brain . The normal homeostasis can maintain by proper conditioning of the nervous system as well mental relaxation process . Regular practice of meditation is linked with changes in thickness of subset of cortical regions associated with somatosensory, auditory, visual, and interoceptive processing .During the actual act of meditation, the activation of right hemisphere is seen $[11,12]$.During active meditation state, many changes linked with the frontal lobe were noted. This area is specifically involved with the focus of attention [13] . Age-related thinning of the frontal cortex may be brought down by regular meditation process . Changes in cortical thickness could be owing to greater arborization per neuron, raised regional vasculature or increased glial volume [14-16].

Bodily attention and visceral awareness is associated with right anterior insula. Increased capacity for awareness is directly associated with increased the thickness of this region [17]. The right hemisphere is important for sustaining attention and it is a center insight meditation [18, 19]. Meditation reflects on cognitive brain functions, such as stimulus discrimination, sequential information processing and short-term memory [20].

\section{CONCLUSION}

It can be concluded that, a short course of meditation has a beneficial effect on the auditory reaction time .The regular practice of meditation can be used as a tool to improve health and well-being of an individual and enhances the reaction time .

\section{ACKNOWLEDGEMENTS}

I express my profound thanks to Yoga trainer Mrs.Asmita Sawant from Patanjali Yog samite and Dr.Manjiri Desai statistician, D .Y .Patil Medical College, Kolhapur .I express my heartfelt thanks to all technicians', teaching \& non-teaching staffs of Dept of Physiology, D .Y .Patil Medical College, and Kolhapur.

\section{REFERENCES}

1. Udupa, K. N., \& Singh, R. H. (1972). The scientific basis of yoga. Jama, 220(10), 1365-1365.

2. Wallace, R. K. (1970). Physiological effects of transcendental meditation. Science, 167(3926), 1751-1754.

3. Wallace, R. K., Benson, H., \& Wilson, A. F. (1971). A wakeful hypometabolic physiologic state. American Journal of Physiology-Legacy Content, 221(3), 795-799.

4. Karambelkar, P. V. (1968). Studies on human subjects staying in an air-tight pit. Indian $\mathrm{J} \mathrm{Med}$ Res, 56, 1282-1288.

5. Vakil, R. J. (1950). Remarkable feat of endurance by a yogi priest. The Lancet, 256(6643), 871.

6. Chhina, G. S. (1974). The voluntary control of autonomic responses in yogis. In Proc Int Union Physiol Sci (Vol. 10, pp. 103-4).

7. Kothari, L. K., Bardia, A., \& Gupta, O. P. (1973). The yogic claim of voluntary control over the heart beat: an unusual demonstration. American heart journal, 86(2), 282-284.

8. Gopal, K.S., Bhatnagar, O.P., Subramanian, N., Nishith, S.O.(1973). Effect of yogasanas and pranayamas on B.P, pulse rate and some respiratory functions. Indian J Physiol Pharmacol, 17: 273276.

9. Madan, M., Rai, U.C., Balavital, V., Thombre, D.P. (1983). Cardiorespiratory changes during savitri pranayam and shavasan. The Yoga Rev, 3: 25-34.

10. Malathi, A., Parulkar, V.G. (1989). Effect of yogasanas on the visual and auditory reaction time. Indian J Physiol Pharmacol, 33: 110·112.

11. Udupa, K.N., Singh, R.H. (1972). The scientific basis of yoga. JAMA, 220:1365

12. Nambinarayanan, T., Thakur, S., Krishnamurthy, N., \& Chandrabose, A. (1992). Effect of yoga training on reaction time, respiratory endurance and muscle strength. Indian $J \quad$ Physiol Pharmacol, 36(4), 229-233.

13. Borker, A. S., \& Pednekar, J. R. (2003). Effect of pranayam on visual and auditory reaction time. Indian journal of physiology and pharmacology, 47(2), 229-230.

14. Bhavanani, A. B. (2003). Effect of yoga training on handgrip, respiratory pressures and pulmonary function. Indian J Physiol Pharmacol, 47(4), 387392 . 
15. Narayana, N. V. V. S. (2009). The effect of yoga on visual reaction time. Indian Journal of Social Science Researches, 6(2), 63-70.

16. Biswas, D. A. (2010). Effects of short term yoga training on pulmonary \& reaction time in students of rural medical institution. JIMSA, 23(2), 71-72.

17. Lazar, S. W., Kerr, C. E., Wasserman, R. H., Gray, J. R., Greve, D. N., Treadway, M. T., ... \& Rauch, S. L. (2005). Meditation experience is associated with increased cortical thickness. Neuroreport, 16(17), 1893.

18. Cohen, D. L., Wintering, N., Tolles, V., Townsend, R. R., Farrar, J. T., Galantino, M. L., \& Newberg, A. B. (2009). Cerebral blood flow effects of yoga training: preliminary evaluation of 4 cases. The Journal of Alternative and Complementary Medicine, 15(1), 9-14.

19. Büssing, A., Michalsen, A., Khalsa, S. B. S., Telles, S., \& Sherman, K. J. (2012). Effects of yoga on mental and physical health: a short summary of reviews. Evidence-Based Complementary and Alternative Medicine, 2012.

20. Sundar, S., Agrawal, S. K., Singh, V. P., Bhattacharya, S. K., Udupa, K. N., \& Vaish, S. K.
(1984). Role of yoga in management of essential hypertension. Acta cardiologica, 39(3), 203-208.

21. Jore, S. B., Kamble, P., Bhutada, T. B., \& Patwardhan, M. S. (2013). Effect of Pranayama training on audio-visual reaction time. Int $J$ Healthcare Biomed Res, 2(1), 35-7.

22. Khadka, R., Paudel, B. H., Sharma, V. P., Kumar, S., \& Bhattacharya, N. (2010). Effect of yoga on cardiovascular autonomic reactivity in essential hypertensive patients. Health Renaissance, 8(2), 102-109.

23. Critchley, H. D., Wiens, S., Rotshtein, P., Öhman, A., \& Dolan, R. J. (2004). Neural systems supporting interoceptive awareness. Nature neuroscience, 7(2), 189.

24. Goldstein. J., Korneld, J. (1987). Seeking the Heart of Wisdom: The Path of Inside Meditation. Boston: Shambhala Publication.

25. Craig, A.D. (2003). Interoception: the sense of the physiological condition of the body. Curr Opin Neurobiol, 13(4):500-5.

26. Ospina, M. B., Bond, K., Karkhaneh, M., Tjosvold, L.,Vandermeer, B., Liang, Y. (2007). Meditation practices for health: state of the research. Evid Rep Technol Assess (Full Rep), 155:1-263. 